\title{
Asian Americans: Factors Influencing the Decision to Study Abroad
}

\section{J. Scott Van Der Meid}

Brandeis University

\section{Introduction}

As our global society becomes increasingly interconnected, people from all cultures, races and ethnicities have more contact with other parts of the world. To be an informed citizen in this society requires an understanding of other cultures and societies. International educational exchange is one avenue that allows students from all over the world to develop an international understanding by experiencing life in a new culture or country. Participants in study abroad programs, however, do not come from all spheres of U.S. society. To increase the number of students who opt to study abroad as part of their higher education career, academic institutions must begin to identify ways to increase the participation of under-represented and minority groups in international education exchange.

Once thought of as a privilege for only the predominately white upper class, students of all ethnic backgrounds and socio-economic classes are increasingly choosing to study abroad. However, research into the study abroad options for these new groups of students has not kept pace with the emphasis on multiculturalism and diversity in higher education institutions today. In the past 15 years, what little scholarly research we have has focused attention on the topic of under-representation in study abroad. This interest evolved on the heels of discussions of diversity and multiculturalism in the late 1980s. In most cases the term "under-represented," instead of the word "minority," is used to describe groups of students who have lower levels of participation (for the purposes of this study, in study abroad) than their levels of enrollment in higher education. 


\section{J. Scott Van Der Meid}

However, most research and published materials on under-represented students deal with African American students and students with disabilities.

This study aims to clarify the influencing factors for Asian American students when making the decision to study abroad. By understanding the influencing factors, efforts could be made to help increase the overall participation of students in study abroad and, more specifically, increase the rate of participation of Asian Americans.

\section{Asian Americans in Higher Education: Background and Review}

Asian Americans are one of the least understood ethnic groups in the United States. As Juanita Lott explains,

The Asian American category encompasses a broad and varied range of populations from fourth-generation, upper-middle-class Japanese Americans to newly arrived Southeast Asian refugees on welfare. Generalizations of such distinct populations must be made with caution. In addition, interethnic and interracial unions are increasing, especially among Asian Americans, calling into question the notion of mutually exclusive groups. Finally, the changing socioeconomic profile of Asian Americans is much closer to a non-Hispanic White majority than to other racial ethnic minorities. ${ }^{1}$

Asian immigrants arrived in this country came in two distinct waves. ${ }^{2}$ The first group came primarily for economic reasons, while the second wave saw more forced immigration from war-torn homelands. These separate waves of immigration have created a semi-divided Asian American community in which some Asian American families are more established in the U.S. than others. Chinese, Japanese, Korean, Filipino and Indian families have been here several generations and are more assimilated into U.S. culture than recent refugees from Laos, Cambodia and Vietnam. As a result, different socio-economic levels exist within an ethnically heterogeneous community.

Asian Americans constituted the fastest growing ethnic group in the United States from 1970 to 1990, according to the U.S. Census.They 
Frontiers: The Interdisciplinary Journal of Study Abroad

have doubled their population for the past three decades, from 1.4 million to 7.3 million. $^{3}$ Based on the success of first-wave Asian-immigrant families, there is a "model-minority" myth, perpetuated by the media. Nowhere is this myth more prevalent than in the views of the white majority toward Asian Americans in higher education. In 1991 Eugenia Escueta and Eileen O'Brien published their research brief, which highlighted the discrepancy between reality and myth.

The media has labeled Asian students in America as 'the model minority,' yet research indicates that this stereotype has hidden the academic difficulties faced by many Asian Americans_-particularly members of certain groups. 4

While there are differences among certain ethnic groups, Escueta and O'Brien's findings show that Asian Americans had a higher level of participation in higher education than any other group in the U.S. In 1990, 40 percent of all Asian Americans, ages 25 and above, had at least four years of college, almost double the figure for whites (23\%), though this rate of education does not exist for all the Asian American ethnic groups. ${ }^{5}$ When studying Asian Americans, their perceived success in higher education and their rate of participation in study abroad programs, it is important to note this variation of rate within this community.

Research from the fields of Asian American studies and education provides a better understanding of the experiences of Asian Americans in U.S. higher education and how study abroad fits into that experience. Three main themes emerge from the literature: racial category injustices, the myth of success, and realities for Asian Americans in higher education today.

When different ethnic minorities are combined into a single racial category, the heterogeneity of the community is seldom acknowledged. Several authors and scholars have addressed this issue, as it applies to Asian Americans, in greater detail. Juanita Lott's book, Asian Americans: From Racial Category to Multiple Identities, clearly articulates the injustice done when the many diverse Asian ethnic groups are combined into the racial category of "Asian American." Wendy Walker-Moffat continues to clarify this injustice. Her book, The Other Side of the Asian American Success Story, outlines the problematic nature of having one category, thereby ignoring the significant differences in academic achievement by 


\section{J. Scott Van Der Meid}

the ethnic subgroups. Jayjia Hsia (1988) outlines the differing ethnic groups and their degree of achievement in institutions of higher education, further proving that the one racial category glosses over disparities in the community. Taking into consideration the above discourse, this study will use the term "Asian American," but it seeks to show as many differences between ethnic subgroups as possible, given the demographics of study participants.

The second important theme to emerge from the literature is the debate around the myth of success. A commonly held stereotype maintains that Asian American students do not need any special assistance or attention because, on average, they are more successful in academia than the general student population. Asian Americans: Opposing Viewpoints contains two articles that debate both sides of the success issue. David Bell claims that, despite some differences in success among ethnic groups, Asian Americans, as a whole, are improving their standing in U.S. society. Bell's claims devalue the ethnic groups, like the Cambodians and Laotians, which are doing very poorly in academic settings. The opposing view, offered by Deborah Woo, maintains that the success myth overlooks the problem faced by Asian American women, making gender another issue that interfaces with the myth of success among Asian Americans. A study conducted in the early 1990s by Northwestern University to see why Chinese, Korean and Japanese American students had such a high rate of academic success in secondary education (in Greenfield's Cross-Cultural Roots of Minority Student Development), further illustrates the success myth. The three ethnic groups chosen in the study have the longest established history in the United States, and research has shown that the longer an ethnic group is in the United States, the higher the success rate for people in that group. Thus, those Asian American families who are less wellestablished in the United States may show greater reluctance for their children to study abroad, because the focus is on becoming better established in the United States. Jayjia Hsia's extensive work, Asian Americans in Higher Education and at Work, outlines Asian Americans' ability on college entrance exams and the achievement levels during high school that affect entry into higher education institutions.

Research specifically on Asian Americans and higher education helps to clarify the diversity found in this ethnic group and highlights the third theme in the field, realities for Asian Americans in higher education. 
Frontiers: The Interdisciplinary Journal of Study Abroad

Hsia's research deals with the aspirations, enrollment and major fields of study for Asian Americans, the achievement factor in higher education itself, and it presents information about occupation data and income levels after graduation. Hsia's analysis suggests, among other things, the disproportionate achievement levels of the different ethnic sub-groups within the ethnic label of Asian American. Escueta and O'Brien, in their article Asian Americans in Higher Education: Trends and Issues, provide further clarification on the realities of Asian Americans in higher education. Using the 1990 Census, they present statistical data on student enrollments, degrees granted, Asian Americans holding faculty positions, and the resulting implications of the findings. Finally, trends in the admission of Asian Americans in colleges and universities are examined by L. Lingchi Wang. Highlighting historical patterns of enrollment, including breaking down the patterns into groupings by class and national origin, Wang goes on to discuss future trends and emerging issues that Asian Americans face in the education arena in the $21^{\text {st }}$ century.

The above literature on Asian Americans may contain little direct insight into the study abroad experience, but it does begin to unlock the experiences of Asian Americans in higher education. However, it does provide this study with a context in which to locate the Asian American study abroad experience.

\section{Factors Influencing Study Abroad Participation}

Differential participation rates are determined by a variety of factors, both in the general student population and with under-represented student groups. Factors that influence a student's decision to participate in study abroad are as varied and many as the number of students themselves. Some research has been conducted to analyze these factors, including studies on the general study abroad population as well as some on under-represented groups, such as African Americans. Still, there is a need for more in-depth study of this general topic.

The factors in the general student population, which influence a student's decision to study abroad include (in no particular order): limited commitment to international education; insufficient institutional and student funding; inadequate preparation in foreign languages and lack of 


\section{J. Scott Van Der Meid}

knowledge of other cultures; curricular requirements on campus; limited support services on campus and abroad; and inadequate information on opportunities for education abroad. This research comes from the only statewide survey on study abroad to be conducted to date, the New York State Task Force on International Education, which collected data from statewide institutions during the 1995-96 academic year. Since New York represents more than 10 percent of the national undergraduate study abroad population, this research is of value for both national and regional demographics. Ethnic background was not a category recorded for this study and there is no explanation given for the exclusion.

Several articles and two known studies have been published on the factors that hinder ethnic minority participation in study abroad. Though similar to the factors that influence the general student population, these studies reveal that some groups are affected by additional factors.

Previous findings indicate that funding is a major roadblock that prevents many ethnic minority students from studying abroad (Heimbroff, 1993; Mattai and Ohiwerei, 1989). Often, campus funding does not apply to overseas study and for ethnic minority students, parttime jobs, which provide additionally needed funding, keep students from leaving for an extended period of time. A plurality of minority students in a Northeastern University study (23\%) listed financial concerns as the top factor influencing their decision to study abroad. ${ }^{6}$

Fearing discrimination overseas is also a factor for some ethnicminority groups (Carter, 1991; Heimbroff, 1993). Based on the amount and type of discrimination faced in the United States, some students do not wish to travel to another country and face more types of discrimination, especially if the country is thought to be racist based on reports in the U.S. media or from returning students' accounts.

Linked to the fear of discrimination is the fear of travel to unknown areas (Heimbroff, 1993; Mattai and Ohiwerei, 1989). Evidence suggests that ethnic minority students are reluctant to travel to areas that do not have familiar social organizations, such as community centers, schools and churches, at the destination site. Mattai and Ohiwerei claim that the presence of relatives and friends is thought to play a supportive role in the face of racial discrimination and, thus, African American students would be reluctant to study abroad in environments where this support did not exist. ${ }^{7}$ Finding ways to reach out to ethnic communities at the destination 
Frontiers: The Interdisciplinary Journal of Study Abroad

sites could help solve this problem.

Another factor deals with the anxiety over language difficulties in foreign countries. Studies have shown that ethnic minority students place language difficulties high on their list of reasons for not studying abroad (Heimbroff, 1993; Carter, 1991). Study abroad programs located in foreign countries where the language of instruction is not English are unpopular with such students.

A common thread in most of the factors discussed so far is the minority students' lack of reassurance about their abilities in a study abroad program. Mattai and Ohiwerei point out the lack of peer mentors and information networks for minority students about study abroad issues. The lack of some or all of the various support elements mentioned above, as well as a lack of faculty encouragement, support from family and friends, shared knowledge from returned ethnic minority participants, and the lack of ethnic minority students appearing in study abroad promotional materials, all contribute to the perception that study abroad is not for ethnic minority students.

Closely connected to reassurance is promotion (Carter, 1991; CIEE, 1991). Without promotional initiatives that seek out ethnic minority students, many such students do not even know that study abroad programs exist. The Northeastern University study showed a majority of those surveyed $(55 \%)$ had no knowledge of international education program offerings at the institution.

Other factors influencing minority student study abroad participation include the education level of minority students, choice and availability of program offerings overseas, and family and social constraints. For African Americans, the relatively high percentage of students who do not finish a four-year degree program prohibits many from studying abroad in their junior year. Most study abroad programs are located in Western Europe, a heritage destination for white students, but not for many minority students. Family and social constraints to stay in the United States and help the family establish themselves in this country often inhibit newly-arrived immigrant groups from participation in study abroad. All three factors might also have influence on Asian Americans and their decisions about study abroad.

These findings highlight some of the factors that inhibit access to study abroad participation for some under-represented groups. While it 


\section{J. Scott Van Der Meid}

should not be assumed that these factors are the same as for Asian Americans, they do serve as a benchmark for comparison with the results of this study.

\section{Methodology}

This study was conducted over a period of one year and included five components: an examination of previously published literature in the field of international education and an analysis of Asian American enrollment data in U.S. higher education; two Web-based questionnaires for Asian American students enrolled in U.S. academic institutions; interviews conducted with Asian American students who had studied abroad and those who had not; a comparison of the results from two questionnaires; and an analysis of how this study can aid in further understanding the concerns and influencing factors of Asian Americans for use by personnel in both U.S.-based study abroad offices and at overseas sites.

In seeking to learn more about Asian Americans and the field of study abroad, it is important clearly define "Asian American." As with any racial category, disagreement persists around an exact definition. For the purposes of this study, "Asian American" will refer to those students raised primarily in the United States who self-identify as Asian American. "Study abroad programs" refers to academic study on programs run by U.S. academic institutions in a foreign country, or the direct enrollment in a foreign university by a U.S.-based Asian American student.

\section{Questionnaires}

Information was sought from Asian American students in four different areas: family background, educational background, students' experiences overseas and a general demographics section, which helped to illustrate the differences between ethnic subgroups among Asian Americans.

Two different questionnaires were used. The first one was for Asian American students who had not considered study abroad as an option in their academic careers (Non-Study Abroad questionnaire). The other questionnaire was geared towards Asian American students who were currently or had in the past participated in abroad programs (Study Abroad questionnaire). 
Frontiers: The Interdisciplinary Journal of Study Abroad

\section{Respondents and Questionnaire Response Rates}

This project aimed to reach Asian American students from a crosssection of academic institutions and major fields of study. Student respondents were sought from across the United States, including Hawaii. A total of 153 questionnaires were returned 78 from the Study Abroad and 75 from the Non-Study Abroad group.

Both questionnaires for this project were located on a website, so they could be accessed by students from across the United States and overseas. Since only electronic questionnaires were used in the final study, the respondent rate had to be determined by counters on the website. The first counter was located on the main page of the website; each survey also had a counter attached to it. By comparing the number of surveys received by the author to the number of "hits" (the number of times a page is viewed) on a given survey page, a return rate of participation could be determined. Some hits made by search engines and random Web surfing must be accounted for in analyzing this data. The Study Abroad questionnaire had 234 hits on its web page during the four months of data collection. With 78 completed questionnaires, returned via electronic mail, the overall return rate for this group was 33 percent. In contrast, the Non-Study Abroad questionnaire had 150 hits on its web page during the collection period. With 75 completed questionnaires, returned via electronic mail, the return rate for this segment of the study was 50 percent.

Although the return rate for the study abroad group is lower than that for the Non-Study Abroad group, there are at least two possible explanations for this discrepancy. The Study Abroad questionnaire was listed first on the website and, therefore, the "curiosity factor" (people on the Internet, surfing into the page) might account for fewer questionnaires being completed. Also, students who had not studied abroad could have mistakenly picked the wrong questionnaire, clicking on the first link for their first choice before clicking on the correct survey.

\section{Results}

Reasons to Study Abroad

The reasons a student decides to study abroad are varied but for the 


\section{J. Scott Van Der Meid}

Asian American students in this study, the most popular reason was the desire to take advantage of an opportunity to be overseas. To learn about a new culture was the next most common reason, followed by the desire to improve language skills. Being away from school ranked fourth, while the desire to learn about one's own cultural roots ranked fifth. Taking electives, as well as fulfilling major/minor requirements, were both ranked sixth. The least common reason for studying abroad was the desire to visit relatives overseas.

Table 1. Asian American Students: Reasons to Study Abroad (Mean)

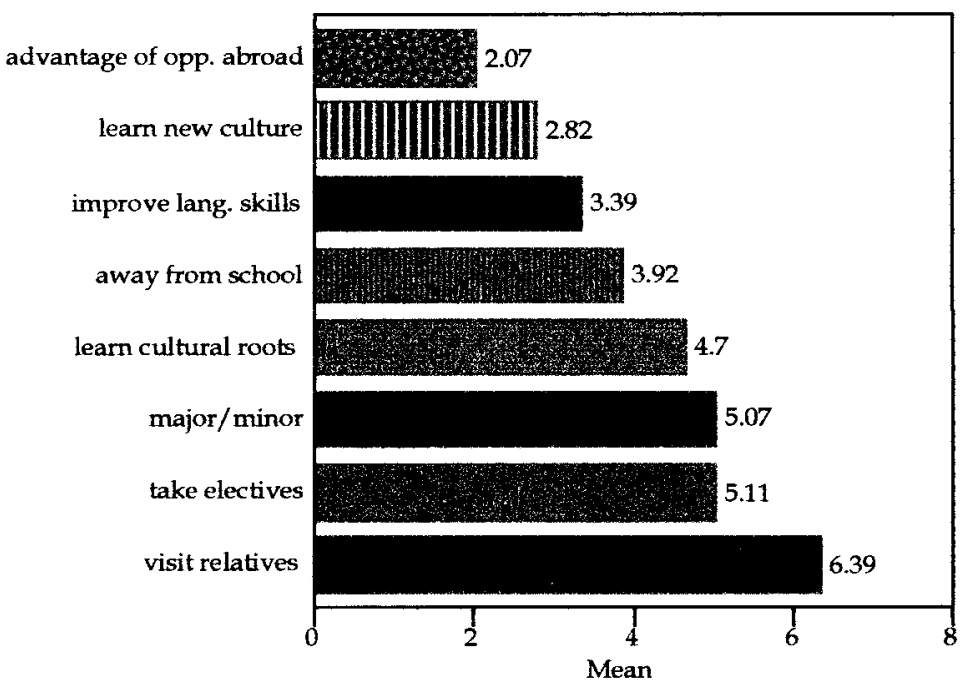

The lower the mean, the more influence a reason had.

Program location also has an impact on whether students study abroad. For those Asian American students who went overseas, the country of destination was as diverse as the group of Asian American students itself. There were 22 countries represented, with an additional category for those visiting multiple countries. The most popular destination was England (22\%), followed by Taiwan (10\%). In addition, another 10 percent of the students went to multiple destinations: more than one country on the same program and/or going on more than two different study abroad programs during the student's academic career. The majority of 
Frontiers: The Interdisciplinary Journal of Study Abroad

students in this category went to one Asian country and to one European country. Japan received 9 percent of the student group, while France and China each saw 7 percent of the student group study abroad respectively. With the exception of England and France, the top countries for Asian Americans were all in Asia. These figures for Asian Americans do not parallel the top 10 countries for the general study abroad population. Thus, an influencing factor in an Asian American student's decision to study abroad is whether or not the program is located in an Asian country. With the majority of students studying in Western Europe, institutions looking to increase the number of Asian Americans going abroad should consider identifying program locations in Asia.

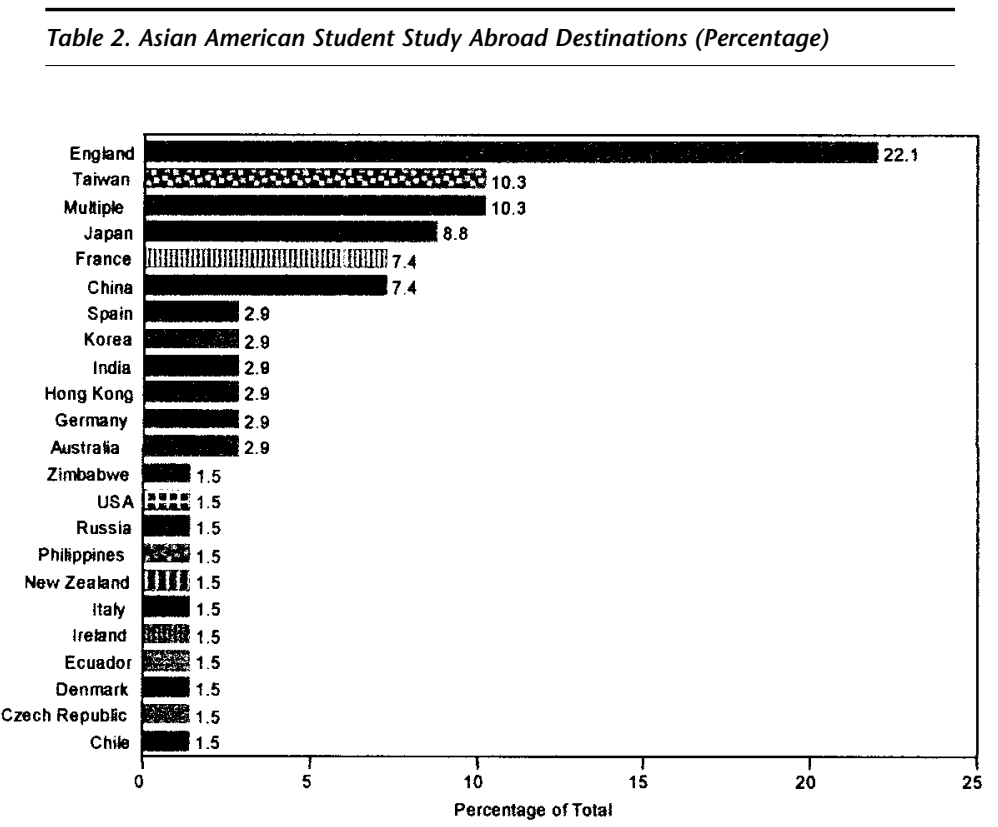

When students were asked they chose to study on their selected program, the majority ranked "location" as the primary reason. The second most important was the "other" category, which included reasons such as the opportunity to use a foreign language or to pursue a family and/or cultural interest. In some instances there was no choice involved; the program was the only possible offering at a student's institution. "Academics" ranked third, while "having a friend going as well" was the least popular reason for choosing to study abroad 


\section{J. Scott Van Der Meid}

\section{Family and Immigration}

Several factors that influence an Asian American's decision to study abroad relate to his or her family and how long they have resided in the United States. Research has shown that, in general, Asians value family greatly. ${ }^{8}$ This was true for both the Study Abroad and Non-Study Abroad students, both had similar family demographics. In the Study Abroad Group, 95 percent came from families with both a mother and a father, and 44 percent of students had at least one sibling. In the NonStudy Abroad, group 91 percent had both a father and mother, while 43 percent students had a sibling.

Research on the success rate of Asian Americans in higher education links the amount of time a student's family has resided in the United States to a student's choice of a major field of study and subsequent career plans. ${ }^{9}$ In this study, students were asked how many generations of their families were born in the United States. No differences were noted between the groups; both had similar distributions of generations born in the U.S. (Table 3). For families of students who had studied abroad, the number of generations born in the United States ranged from zero to four. The largest majority of study abroad students ( $40 \%$ ) were born in the United States, but they had parents who were born overseas. 38 percent of the study abroad students had parents who were born in the United States, making the Study Abroad students second-generation, U.S.-born Asian Americans. The students studying abroad were mostly from newly-established families in the United States. Of the 38 percent of Study Abroad students born overseas, the median age at the time of immigration to the United States was 4 years old.

The plurality of Non-Study Abroad students (44\%) revealed that one generation of their families had been born in the United States. Nearly 32 percent of the Non-Study Abroad students did not have any family members who were born in the United States, making them either immigrants or the children of immigrant parents. Not included in these figures are those students who were adopted or whose parents' families came to the United States at different times from each other. With 76 percent of the Non-Study Abroad students having recently arrived in the United States, the families in this group, as well as the Study Abroad group, have had less opportunity to establish themselves. 
Frontiers: The Interdisciplinary Journal of Study Abroad

Table 3. Distribution by Generation of Asian Americans (Number)
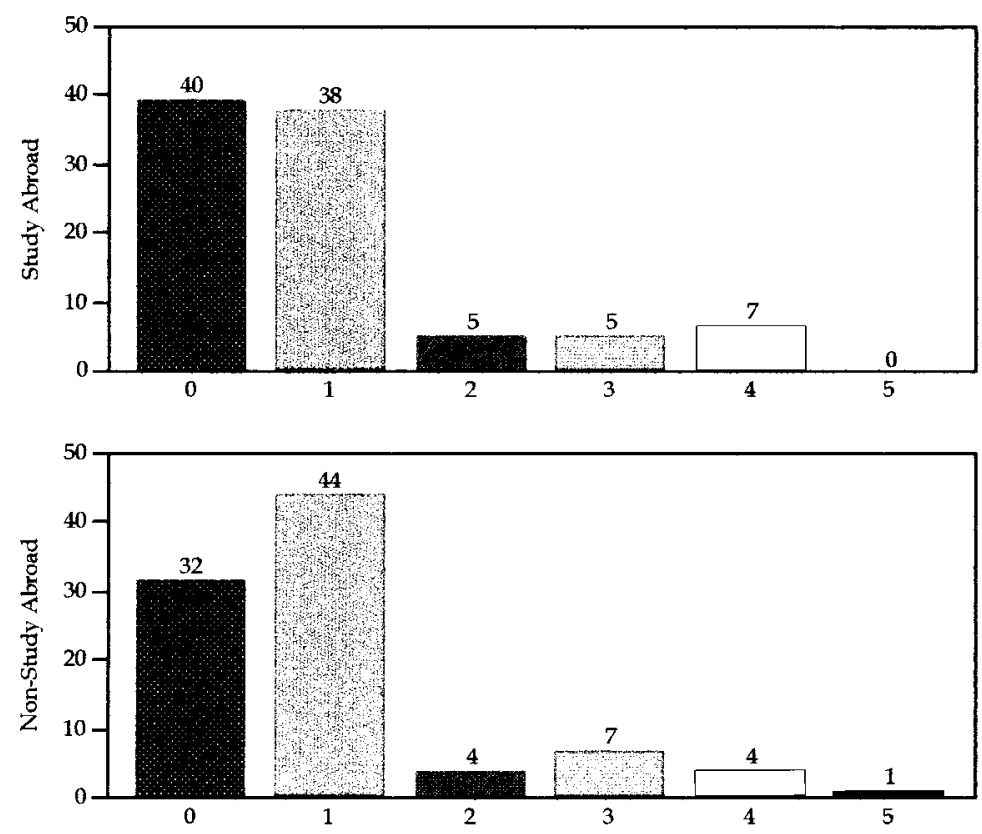

A zero value for generation means the student immigrated with his or her parents to the U.S. Students who were adopted or whose parent's came to the United States at different times are not listed in this chart. Sample Size $=72$.

While evidence suggests that the amount of time residing in the United States is related to the degree of success in higher education, the data from this study, shows that generation has little effect on Asian Americans' decision to study abroad.

\section{Birthplace, Hometown and University/College Locations}

Whether or not a student was born in the United States and where the student grew up might have an influence on the decision to study abroad. A common stereotype reinforces the notion that a student's geographic location, in part, determines his or her knowledge about educational opportunities and the access to such opportunities. Asian Americans, when first arriv- 


\section{J. Scott Van Der Meid}

ing in the United States, tended to cluster in specific regions of the country and enroll in select institutions of higher education. Over time, the Asian American population has spread into most regions of the country and enrollment in higher education institutions has seen an increase in diversification.

The Asian American students in this study have grown up in a variety of U.S. states. As might be expected, there were high concentrations of students on both the West and East coasts, where sizable amounts of Asian American communities exist. The largest concentrations for both the Study Abroad and Non-Study Abroad groups were in California (16\% and $22 \%$ ) and New York (11\% and $14 \%$ ). Table 4 shows the percentages of students in both groups for each state represented.

Since many students choose to attend universities or colleges in different states or regions from where they grew up, the distribution of states based on Asian American enrollment in higher education institutions is also

Table 4. Respondent's Home State (Percentage)
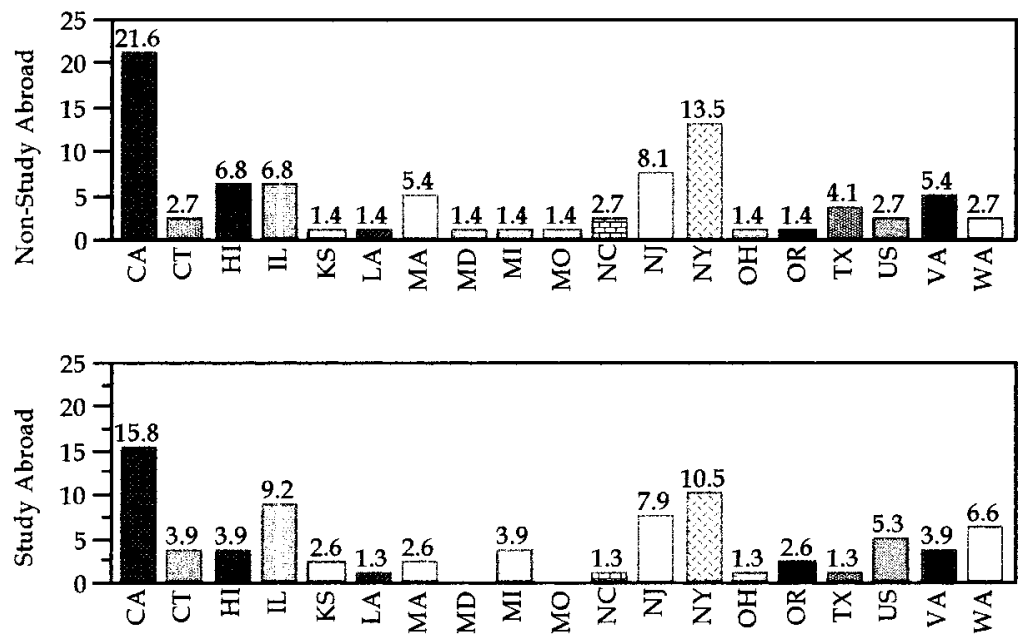

important. Nationally, the U.S. West Coast and Hawaii have the largest percentages of Asian American residents and the largest percentages of Asian American students enrolled in higher education. Table 5 shows the percentage of students in higher education in each state represented in the study. The plurality of Asian American students, both Study Abroad and Non-Study Abroad, attended university in California (30\% and $28 \%$ ). Massachusetts was second for the Study Abroad group (20\%) and third 
Frontiers: The Interdisciplinary Journal of Study Abroad

for the Non-Study Abroad group (11\%). In reverse order, Illinois was third (9\%) for the Study Abroad group and second (16\%) for the NonStudy Abroad group. New York (9\%) tied for third with Illinois with the Study Abroad group. While the Study Abroad sample came from 17 different states and the Non-Study Abroad sample came from 20 different states, concentration was evident in places where universities and/or colleges had a strong Asian American student group with a website supporting their organization. As with the Non-Study Abroad group, announcements about this study were sent to student groups that could be found through Web search engines or through personal contacts. The number of Asian American students enrolled at institutions of higher education in Hawaii should be noted. ${ }^{10}$ The Study Abroad Group had zero enrolled, while only three percent were enrolled among the Non-Study Abroad group.

Table 5. Asian American Respondents in Higher Education Institutions (Percentage)
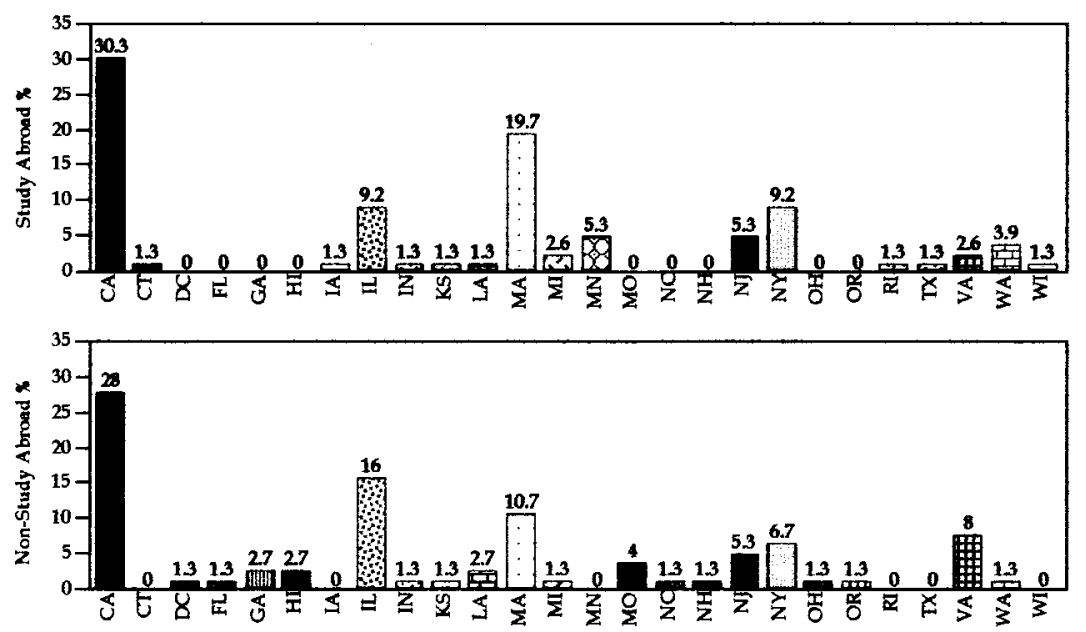

The location of the student's home institution had little influence on the student's decision to go overseas. While overall the New England region sends the highest percentage of students abroad, the Asian American students who studied overseas came from a variety of states across the country. These states paralleled the national trends of Asian American student enrollment with the exception of Hawaii, which had little representation in this study. 


\section{J. Scott Van Der Meid}

Reasons for choosing to attend a particular institution might explain why Asian American students do or do not study abroad. Students were asked to rank eight factors in terms of their influences in choosing their academic institutions. Do Asian Americans, like other ethnicminority groups, seek out places with people from similar cultural backgrounds, or do other factors influence their decision to attend a particular institution. And, if they do seek out this environment, might this be associated with their decision about whether or not to study abroad? Table 6 shows the mean scores of influencing factors for both groups. Among the Study Abroad students, the number one ranked influence was the academic offerings at the institution, followed by the reputation of the institution. The third most influential factor for Study Abroad students was where the institution was located, followed by the amount of financial assistance available. For the Non-Study Abroad students, the top three ranked influences were the same, except in a different order. Non-Study Abroad students listed reputation as the primary influence in choosing an institution, followed by its location and academic offerings. The size of the Asian American student population on campus was the least influencing factor for both groups when making their decision to attend university. The influencing factors chosen do not support the claim that finding a similar cultural setting, as is common with African Americans, is important. ${ }^{11}$ However, the Non-Study Abroad group had a higher mean score for the cost of the institution, compared to the Study Abroad group, who were more concerned about financial aid. Study abroad students are concerned about financial aid than they are about costs, whereas NonStudy Abroad students are more concerned about costs than they are about financial aid. 
Frontiers: The Interdisciplinary Journal of Study Abroad

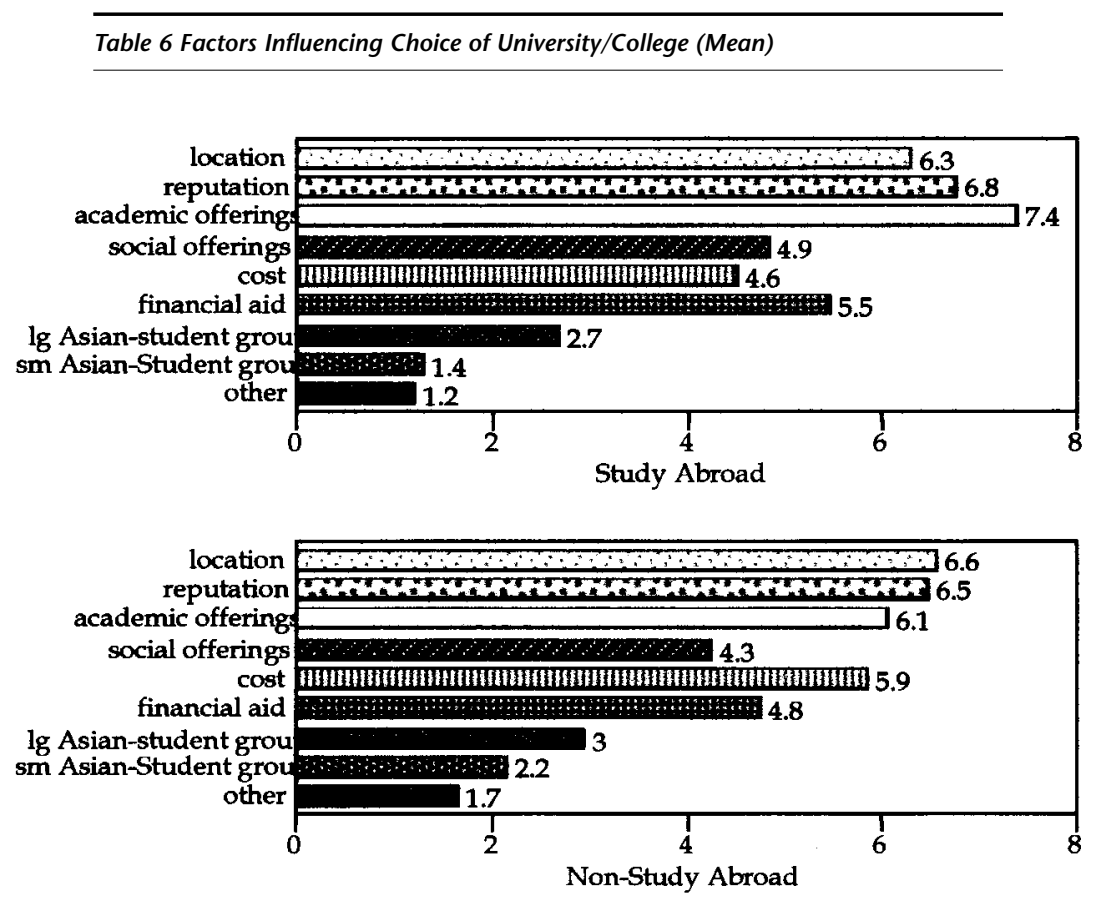

\section{Personal Qualities}

Study abroad selection is often based on an applicant's personal qualities that program administrators either deem as necessary for or as strong indicators of a successful experience overseas. Study Abroad students, like the Non-Study Abroad students, were asked to check as many qualities that applied to them from a list of 22 adjectives to see if the two student groups reported significantly different qualities. See Table 7 for the distribution of self-described personal qualities. The most chosen trait for both student groups was being "open-minded." "Independent" and "curious" both ranked in the top five personality traits most often checked for both groups. "Timid" had the least amount of responses in both groups of students. Study Abroad students saw themselves as being "open-minded" (88\%), "independent" (71\%), "curious" (71\%), "motivated" (70\%), "self-reliant" (66\%) and "academic" (63\%). They were less likely to see themselves as "timid" (16\%) and "aggressive" (25\%). Non-Study Abroad students saw themselves as being "open-minded" (84\%), "generous" (68\%), "independent" (67\%), “curious" (64\%), "funny” (59\%) and 


\section{J. Scott Van Der Meid}

"self-reliant" (59\%). They were less likely to see themselves as "timid" $(19 \%)$ and "aggressive" (20\%).

Table 7. Personal Qualities (Percentage)

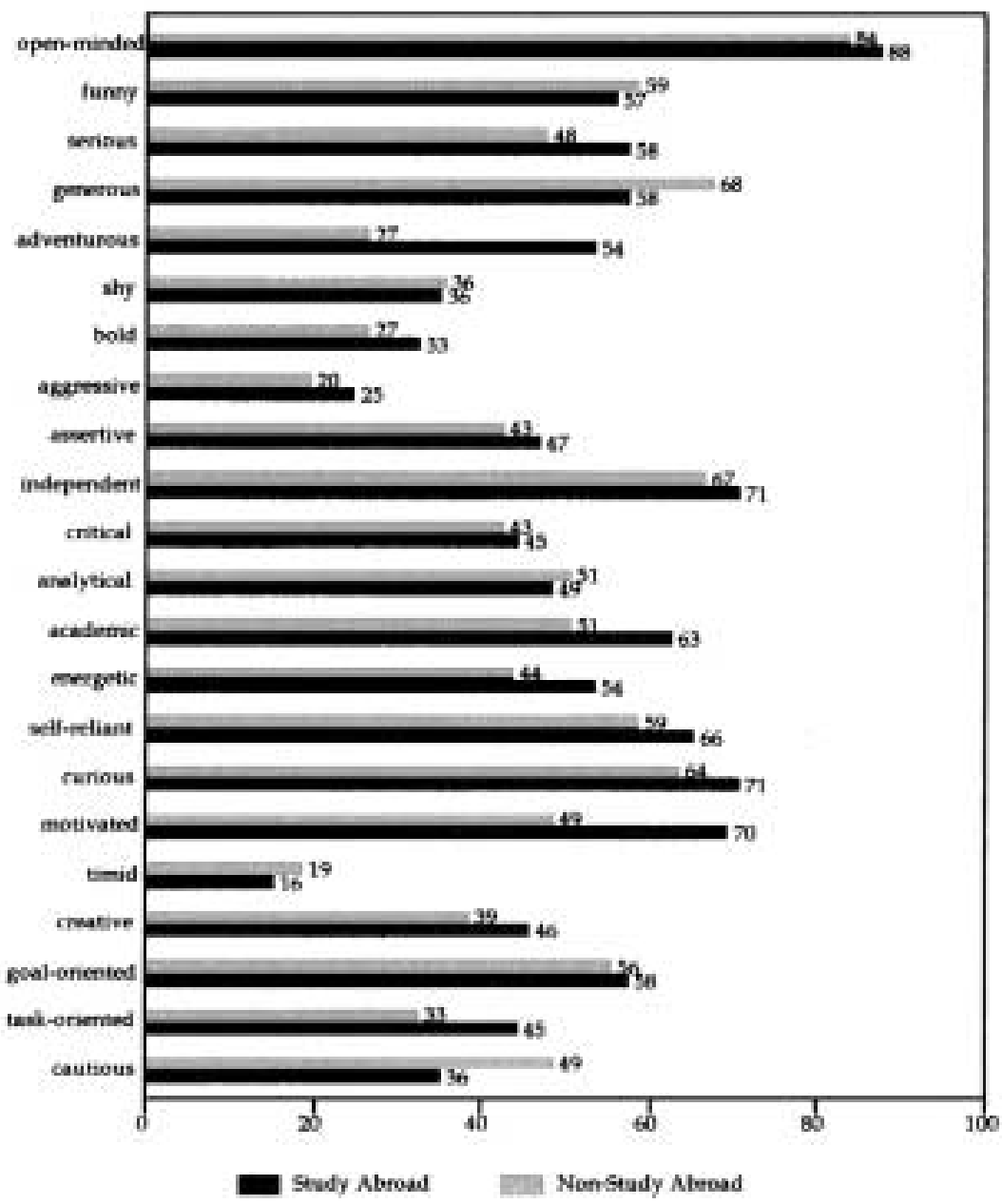

There were some notable differences between the two groups. Overall, the Study Abroad group checked more qualities, and a significantly higher percentage of themselves-identified as being serious, motivated, energetic, academic, adventurous and task-oriented. These qualities support the notion that study abroad is for serious, academic students who 
Frontiers: The Interdisciplinary Journal of Study Abroad

possess energy to handle experiences abroad. The qualities "adventurous" and "motivated" had the greatest difference in their percentages between groups. This finding reinforces the belief that students who study abroad must be strongly motivated and ready for the adventure that comes with unknown situations overseas. For the Non-Study Abroad group, students showed higher percentages for being "generous" and "cautious." Being cautious highlights the student's desire to take less risk in his or her life and, thus, a study abroad experience would therefore not be a principal goal while completing an educational degree.

\section{Ethnicity}

Since the Asian American category includes peoples from diverse ethnic backgrounds, ethnicity was considered in order to see if different patterns emerged between the ethnic subgroups as compared to the general study abroad population. In discussing Asian Americans, the importance of looking at the differing patterns among ethnic groups can not be emphasized enough.

According to the 1990 U.S. Census, Chinese (23\%) were the largest Asian ethnic group in the U.S. Filipinos (19\%) and the Japanese (12\%) were the second and third largest groups. On the national level, Koreans constituted 11 percent of the Asian population while the Vietnamese made up 8 percent. ${ }^{12}$ In keeping with national trends, the Chinese made up the largest group of respondents in both the Study Abroad group (41 $\%)$ and the Non-Study Abroad group (32\%). Table 8 shows the ethnic make-up of all Asian American respondents in this study. In second place were different ethnic groups. Koreans made up 15 percent of the Study Abroad group, while the Vietnamese made up 15 percent of the NonStudy Abroad group. Respondents of Indian ancestry (11\%) came in third place in the Study Abroad group, while Filipinos held third place with 11 percent in the Non-Study Abroad group. Included in the "other" category for the Study Abroad group were some students with more than one Asian ethnic background, such as Vietnamese Chinese, Chinese Thai and Chinese Japanese. 


\section{J. Scott Van Der Meid}

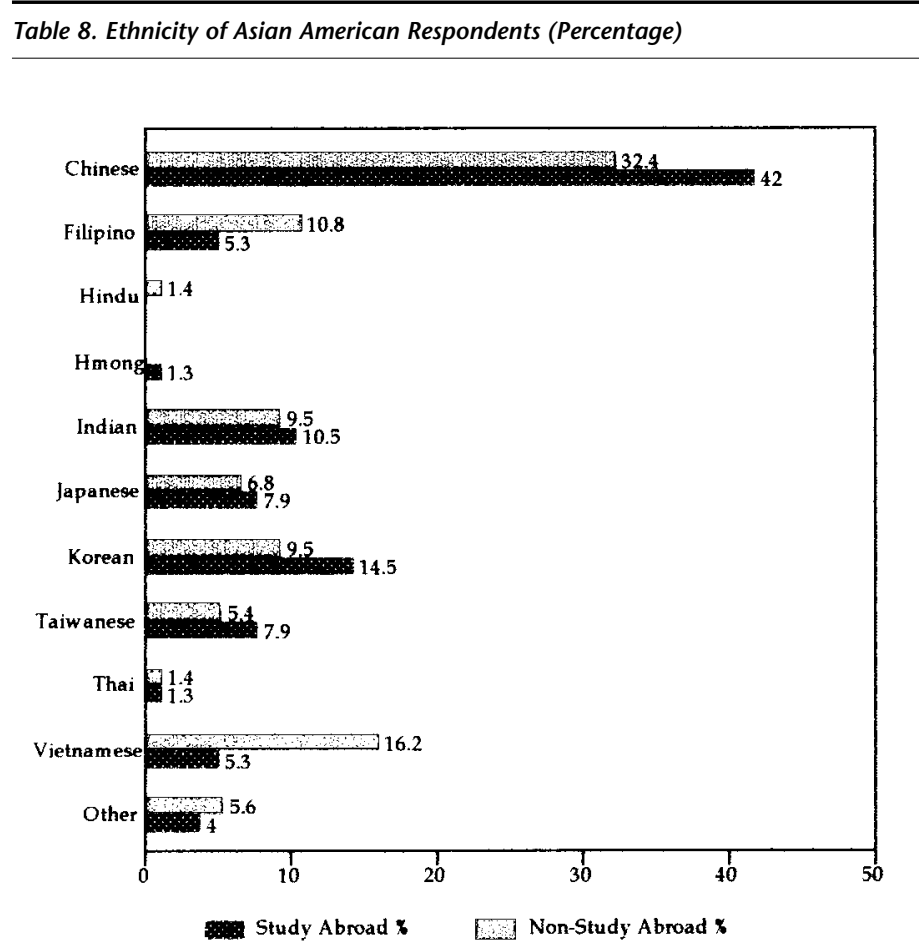

Note: Some students with Taiwanese backgrounds might have listed their ethnicity as Chinese.

The "other" category in the Non-Study Abroad group included Thai, Hindu, Okinawan and some multiple groupings. The ethnic makeup of the study sample does not parallel the makeup of Asian Americans in the United States.

Reinforcing the belief that those ethnic groups that have resided in the United States for less time have lower study abroad rates, the ethnic subgroups of Filipinos and the Vietnamese had significantly fewer students studying abroad than the more established ethnic groups, i.e. Chinese, Korean and Taiwanese.

Sex

The distribution of Asian Americans in higher education based on sex 
Frontiers: The Interdisciplinary Journal of Study Abroad

does not follow national trends. The general student population is 56 percent female and 44 percent male, ${ }^{13}$ while the Asian American population enrolled in institutions of higher education is 49 percent female and 51 percent male. ${ }^{14}$ Neither participant group, in comparison to national figures, shows the same distribution patterns based on enrollment, as seen in Table 9.

Table 9. Distribution by Sex

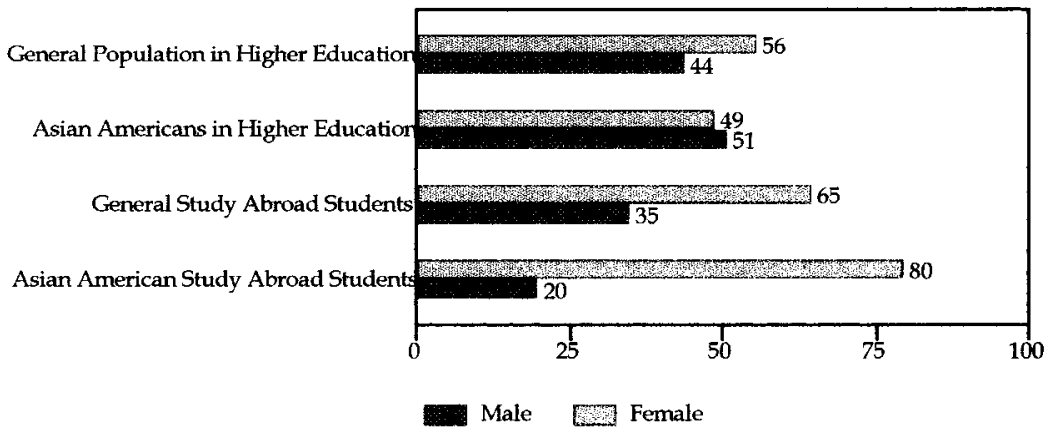

The distribution of participants by sex in study abroad is an important topic. In the United States the majority of study abroad students are females $(65 \%) .{ }^{15}$ This study reveals that the Study Abroad group had a distribution pattern between female and male students similar to the general study abroad population, while the Non-Study Abroad group did not show the expected inverse distribution. In the case of the Study Abroad group, 80 percent of Asian Americans who went overseas were female, while males made up only 20 percent of the group. Since Asian Americans have an almost even distribution between female and male students in higher education, the large difference in participation rates by sex is significant. The Study Abroad group shows an uneven distribution, while the Non-Study Abroad group distribution parallels Asian American enrollment in higher education more closely. This indicates that Asian American men are more under-represented than males in the general study abroad population.

When sex is combined with ethnicity, different distributions of sex make up the various ethnic subgroups for Asian Americans. The percentages of ethnicity by sex for Non-Study Abroad students are shown in Table 10. The Study Abroad group shows a distribution by sex similar to 


\section{J. Scott Van Der Meid}

that of general study abroad participants, but the study does not show a similar distribution for Non-Study Abroad students. The results reveal that the more established ethnic groups send more students abroad. More females than males studied abroad, regardless of their ethnic background, reinforcing the under-representation of Asian American men in study abroad regardless of their ethnicity.

Table 10. Ethnic Background of Study Abroad Students by Sex (Percentage)

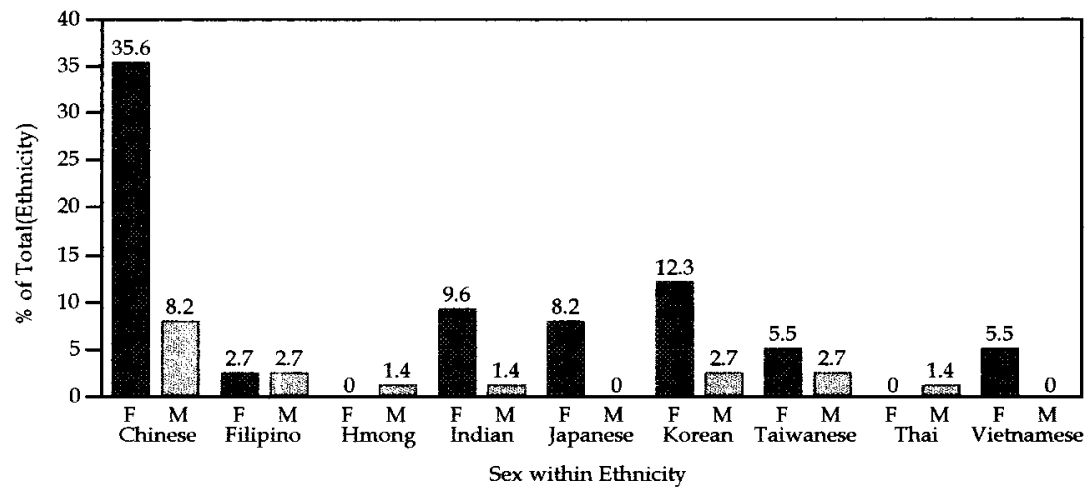

Major Fields of Study

Study abroad advisors believe that a student's major has a strong influence on his or her participation in study abroad. What motivates students to choose a particular major field of study might also have relevance on their decisions to study abroad. This study's results parallel the national trends for Asian Americans and the major fields of study in higher education today. As reported by the American Council on Education, the top three subject fields for Asian Americans are business, engineering and social sciences, in that order. When broken down by sex, men graduate with degrees in business, engineering and social sciences, women graduate with degrees in business, social science and life sciences. ${ }^{16}$

A popular stereotype is that more Asian Americans do not go abroad because they are more likely to major in the natural sciences and other traditionally under-represented major fields of study. However that is not reflected in this study. The fact that the social sciences are popular major fields of study in the general Asian American population and the general study abroad population suggests that a student's major is not the sole 
Frontiers: The Interdisciplinary Journal of Study Abroad

influencing factor in the decision to study abroad.

With the increasing popularity of overseas study, more students with majors from diverse fields have been going abroad. Table 11 shows the breakdown of major fields of study for both Asian American student groups. In the Study Abroad group, the majority of students came from majors in the social sciences $(30.3 \%)$. The second largest category was dual majors (15.8\%), followed by the biological sciences and business with 10.5 percent each. Communications and the arts, as well as health professions, each represented 6.6 percent of the Study Abroad group.

Table 11. Major Field of Study by Group (Percentage)

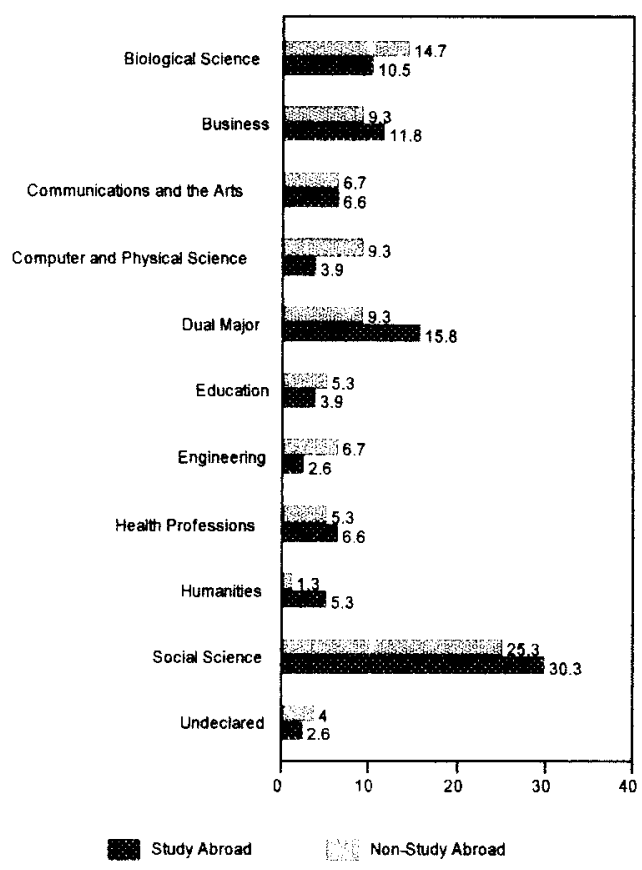

Note: The category 'Dual Major' includes all students whose two majors fall into different fields of study categories.

The largest group of Asian American students who did not study abroad had majors in the social sciences ( $25 \%)$, the same major as the largest group of students who did study abroad. The other significant 


\section{J. Scott Van Der Meid}

majors for the Non-Study Abroad group were in the sciences and education.

Related to the major field of study are factors that influence choice of a major. If a student chooses a major primarily because of a career goal versus, say, the advice of a professor, this might also influence the student's decision to study abroad. The top three characteristics influencing major field choice for the Study Abroad group were "genuine interest in the major," the "student's decision alone," and "future career prospects." In the Non-Study Abroad group the top three factors, according to their mean, were "genuine interest," "future career prospects," and student's "decision alone." The least important influence on the choice of major for both groups was "faculty/advisor influence".

Both Asian American student groups listed the same three influencing factors, in different order, when choosing their major. The biggest factors that were not listed as important were influence from parents, peers and faculty. The data suggests that students are making the decision themselves out of genuine interest and future career prospects.

\section{International Travel}

One of the survey questions asked the respondents to indicate which world regions they had visited, and it was designed to access the amount of international awareness the student possessed. While the question was not precise enough to give the detailed analysis originally desired, it does provide a basic indicator of exposure to other cultures around the world. Overall, 100 percent of the Study Abroad student group had traveled internationally. What is unclear is how many students traveled internationally when the study abroad period is excluded from the findings. Taking the country of study abroad participation and subtracting it from the student's travel totals makes possible a better comparison. However, this does not take into account those students who may have traveled to the region where they studied abroad before participating in their study abroad program.

Table 12 shows the percentage of international travel by region for both student groups. 89 percent of all Asian American students in the Study Abroad group had been to Asia, while Europe was the second most popular destination $(58 \%)$. Africa remained the region least traveled to with only 2 percent reporting a visit to this area. The "other" category 
Frontiers: The Interdisciplinary Journal of Study Abroad

included one study abroad student's time spent in the Middle East. Because some students listed their time living in the United States and others only listed trips to Mexico and/or Canada, the category North America was omitted from these tabulations.

There were similar results for Non-Study Abroad students. Overall, 83 percent of Non-Study Abroad students had traveled outside the United States, while 17 percent had never left this country. The number one destination for international travel was Asia $(74 \%)$. This figure may be somewhat high, as it is impossible to tell how many of the Non-Study Abroad students counted the time they lived in Asia prior to their family's immigration to the United States. Europe (35\%) was the second most popular destination, followed by Central America and the Caribbean (27 $\%)$ for Non-Study Abroad Asian American students.

Table 12. Students' International Travel Before Study Abroad (Percentage)
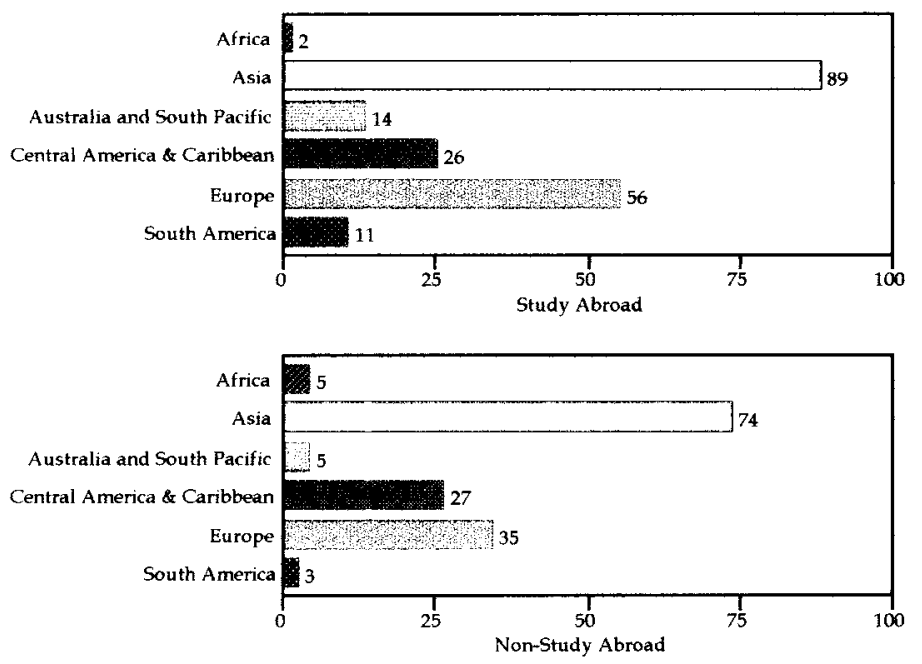

Note: Because some students listed time living in the United States and others only listed trips to Mexico and/or Canada, the category North America was omitted from these tabulations.

Asia was the region most visited for both student groups, supporting the notion that international travel often includes regions of common ancestry and language heritage. The second most commonly-visited region for both groups was Europe, though the Study Abroad students visited the 


\section{J. Scott Van Der Meid}

region, on average, 20 percent more often. Overall, the Study Abroad group had more international travel experience to more areas of the world than those who did not study abroad. Africa remained a region barely visited by either group.

\section{Study Abroad Interest}

Interest in study abroad came at various times for different students. For the majority of Asian American students in the Study Abroad group, high school was the time when they first became interested in study abroad ( $42 \%)$. The second most popular time for 35 percent of the students was in college or university. Both "prior to junior high school" and in "junior high school" represented 11 percent of the respondents. Thus, just over 63 percent of all students who studied abroad had become interested in an overseas experience by the time they finished high school.

For Non-Study Abroad students, two questions sought to gauge their awareness of study abroad and of financial aid support. Awareness of study abroad among Non-Study Abroad students was 100 percent. Those Asian American students who were not interested in the topic of this study were not required to fill out the questionnaire; thus the Non-Study Abroad group is not representative. In terms of awareness of institutional financial assistance for study abroad from their university or college, 68 percent of the students said they knew about such aid. When broken down by ethnicity, Filipinos and Indians had the highest rates of awareness of financial aid at 88 percent and 86 percent respectively, while Koreans had the lowest rate of knowledge about financial aid at 43 percent.

\section{Sharing the Experiences of Asian Americans Overseas}

Utilizing returned students to generate interest in study abroad programs has proven useful. Once a student comes back, he or she proves to be a successful means of spreading the excitement, joy and, sometimes, negative experiences of such opportunities to other students in their peer groups. Because of this, learning about the experiences of Asian American students who have studied abroad or who are currently studying abroad are important factors in prospective students' decisions about whether they, too, should study abroad. To understand better the experiences of 
Frontiers: The Interdisciplinary Journal of Study Abroad

Asian Americans during their time abroad, respondents were asked to disclose the major challenges they faced overseas, their interactions with locals and degree of racism experienced, and their overall experience with the student services provided.

Major challenges were experienced by 67 percent of the students, including homesickness, blatant racial discrimination, communication issues, inability to make friends, overcoming loneliness and adjusting to the lack of a structured environment. As one Chinese student commented,

(along with) the newfound independence that I so much enjoyed came times when I simply wanted to come home and have someone else make the decisions for me... The whole shift from being in a really structured and self-contained environment to a new, unfamiliar territory was a big emotional ordeal.

Another common challenge involved misperceived identity in cases where students may look like local citizens, but are unable to speak the language and understand the cultural values well. As one student said, "People couldn't understand why I didn't speak Chinese as well as the rest of them because I looked Chinese." Another Chinese student had her identity misinterpreted on several occasions in Spain:

Europeans can't tell one Asian from the other. They assume that all Asian people are Japanese. Everywhere I walked on the street, Spaniards would walk up to me and say "Japonesa?" ...Another time, while I was in the police station to get a visa, in order to walk up there, I had to sign in with my passport number. The officer would write my passport number and country of citizenship. As I watched him, he wrote "China" (now, I've never even been to China). I told him to erase it because I'm American and he said back to me, "but you look like a Chinese person."

In previous studies on African Americans, one of the biggest worries reported by students wanting to study abroad was the fear of discrimination in the foreign country. ${ }^{17}$ Asian American students did not have this experience. Table 13 shows the degree of racism experienced by Asian American students overseas: 36 percent didn't experience as much racism overseas as in the United States; 23 percent saw no difference between the 


\section{J. Scott Van Der Meid}

United States and their host countries; and 26 percent said they didn't experience any racism overseas. Fewer than 13 percent felt they experienced more racism, and 2 percent said they experienced "a lot more" racism abroad than in the United States. Because the word "racism" was not defined on the questionnaire, respondents' differing definitions of the term might also have influenced the results.

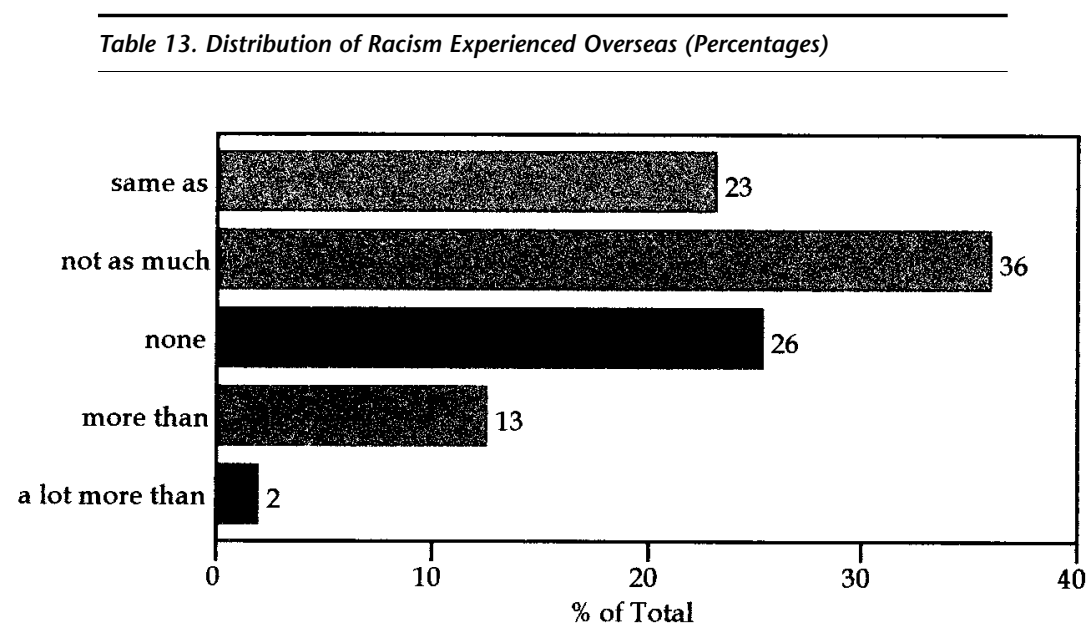

One Taiwanese student expressed his frustrations in applying for jobs in Asia. "As an Asian-American, I was not as welcome in English teaching jobs." Expressions of racism manifest themselves in different ways in other parts of the world than in the ways that students encounter them in the United States. A female student shared her major challenge while in Africa:

I was so accustomed to defending my Americanness [sic] all my life, but in Zimbabwe, where Koreans are extremely loved and Americans are not so well loved, I realized for the first time that it's OK to be Korean. I was never so appreciated for my heritage by non-Koreans before in my life, and it felt great.

Any discussion about racism must be qualified by noting the degree of interaction students have with the local citizenry. More exposure to local people in a given country presents students with more opportunities to experience racial discrimination in that setting. More than half of the Asian American students had a high degree of interaction with the local citizens: 23 percent reported greater-than-average interaction, while 17 
Frontiers: The Interdisciplinary Journal of Study Abroad

percent reported only some interaction. 50 percent of those who experienced "more racism than in the U.S." had "a lot of interaction" with local people at their study abroad site. The plurality of students who had a lot of interaction with the locals experienced the same amount of racism as they experienced in the States. Since both categories were self-defined, it is difficult to draw strong conclusions since each person's definition of racism, as well as the reported degree of their interaction, will vary.

Finally, as with any aspect of a higher education experience, the different support services available to students have an impact on their overall experience. Respondents were asked to rate the support services normally provided when students participate in overseas programs. Student services received an "average" rating from 30 percent of students. Financial aid was rated as both "average" and "excellent" at 23 percent each. Academic advising received an "average" rating from 43 percent of the students. Pre-departure orientation earned an "average" rating (32\%). While the on-site orientation earned the highest rating of all services with 34 percent of the students rating it as "good," the re-entry meeting earned only an "average" rating (30\%). Since no known studies have been conducted on this area for the general study abroad population, comparisons are not possible. The results do suggest, however, that Asian American students do not believe extra efforts are being made to meet their needs.

\section{Reasons Students Did Not Go Abroad}

Finally, the Asian American Non-Study Abroad students were asked to rank the top five reasons why they decided not to study abroad. The highest-ranked reason was that study abroad did not fit into their academic program. The second-highest reason was that students couldn't afford to study abroad. Table 14 shows the mean scores for all the reasons. The "other" category was the third most reported reason, and included reasons such as low GPA, lack of time, "couldn't leave a job" and that students had never considered study abroad as an option. One Chinese student, who had already lived in Saudi Arabia for three years, expressed his decision to stay in the United States:

I basically felt that I was getting the best education in the United States compared to any other country, especially in the 


\section{J. Scott Van Der Meid}

sciences. This did not mean that I thought that other nations were lacking, I just felt that overall, the entire college time spent in the U.S. was needed to fulfill the enrichment of all aspects in my field. By leaving for a semester or two, I would be somewhat short-changing myself on those areas that I would be taking elsewhere. Also, I would have to say that practicality was a big issue, based on family support and time that I would be taking away from being able to accomplish other things like doing research in labs and establishing valuable contacts for the future, especially in places where I knew I would return to do work, such as biotech companies in California.

The fourth reason was that there were no topics of interest offered on study abroad programs, while concern about language difficulties abroad was the fifth most reported reason. The least important reason was a fear of cultural differences, preceded by little support from friends. 57 percent included of students "didn't fit into academic program" on their list of reasons, while 31 percent included "could not afford to go."

Table 14. Reasons for Not Studying Abroad (Mean)

\begin{tabular}{|c|c|}
\hline Didn't fit academic prog. & 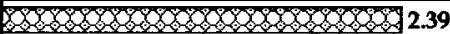 \\
\hline Couldn't afford & 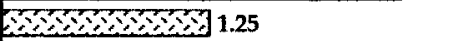 \\
\hline Other & 71.19 \\
\hline Didn't offer topics & 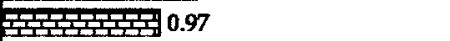 \\
\hline Concern language differences & 0.76 \\
\hline Still considering going abroad & ए] 0.72 \\
\hline Fear of unknown & W0XN30.67 \\
\hline Lack of faculty encouragement & 0.57 \\
\hline Need to work & 0.55 \\
\hline Didn't know others going & 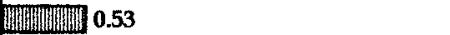 \\
\hline Little family support & 0.39 \\
\hline Fear of discrimination & 0.13 \\
\hline Little friend support & 0.11 \\
\hline Concern - cultural differences & 0.08 \\
\hline & $\begin{array}{ccc}1.0 & 1.5 & 2.0 \\
& \text { Mean }\end{array}$ \\
\hline
\end{tabular}

Generally speaking, the data indicates that Asian Americans are going abroad to learn about a new culture. Several major findings result- 
Frontiers: The Interdisciplinary Journal of Study Abroad

ing from the data analysis reveal factors that influence a student's decision to study abroad. Asian Americans, despite the popular stereotype regarding success in higher education, are not only influenced by their major field of study. The amount of time their families reside in the United States is also not of great influence. However, the fact that study abroad does not fit into their academic programs suggests that something aside from the major inhibits spending time off campus. Personal qualities also differ between those who study abroad and those who do not. The sharing of experiences by those who have returned from abroad with their peers also seems to be lacking. This understanding of the educational background and the experiences of Asian Americans assists in providing a more complete picture of the four-year educational experience of these students and the place of study abroad within that experience.

\section{Conclusions}

Based on this study, the reasons for Asian Americans to study abroad are similar to the reasons why all students study abroad. However, there are factors that influence Asian American students' decisions to study overseas that are unique to this group.

First, let us note several factors that don't appear to play a significant role in Asian American students' decisions to study abroad. Family make up and the amount of time each family has resided in the United States were not different for the two Asian American groups. This discounts the notion that Asian Americans do not study abroad because a large percentage of the students are from newly-arrived families. The relationship between where a student grew up and where he or she chose to attend university or college also was not a significant factor. Enrollment of Asian American students in both groups paralleled the national trends for student enrollment. Another issue that was thought to influence a student's decision to study abroad was the influence of reasons behind the choice to attend a particular university or college. Both groups of students had similar experience distributions, showing that reasons for choosing a particular institution are not a factor that influences one's decision to study abroad. This counters the debate put forward by some that Asian Americans experience more difficulty in applying to colleges and universities because of the restrictions and quotas put on them by admission's policies. 


\section{J. Scott Van Der Meid}

General demographic and personal information about the two student groups revealed some significant findings. Some of the student's selfdescribed personal qualities differed between the groups. For the Study Abroad group, students were more likely to describe themselves as serious, motivated, energetic, academic, adventurous and task-oriented. The Non-Study Abroad group, in contrast, saw themselves as being generous and cautious. This finding reinforces the common view held by study abroad administrators that students who have the qualities of the Study Abroad Group outlined above, will be successful overseas. The majority of students in both Asian Americans groups were Chinese. The Vietnamese and Filipinos were the least likely ethnic groups to study abroad. Since most Vietnamese have come to the U.S. in the last thirty years, this further supports the notion that a shorter amount of time residing in the United States decreases the chance that a student will study abroad.

Asian Americans are often stereotyped as science majors who excel in higher education. However, the Study Abroad group's most popular majors were in the social sciences, dual majors, biological sciences and business. The trend among study abroad students nationally also follows this pattern. The Non-Study Abroad group also mimicked the national student population. The top three fields of study among Asian Americans nationally are business, engineering and social sciences, the same top three fields as the Non-Study Abroad group of students. A large portion of the Non-Study Abroad students were social science majors and traditionally social science major tend to be the majority of students going overseas. The reasons that this group of students did not go abroad needs further examination, because major field of study is not the prohibiting factor in this case. Overall, reasons for choosing a major were not a determining factor for the student groups decision to study abroad.

Other factors influencing an Asian American's decision to study abroad include previous international travel experience, program location and the influence of returned Asian American students who share their experiences with potential study abroad participants. The results of this study show that more international travel experience inclines students to study abroad. This study found that the Study Abroad students had traveled overseas more than their Non-Study Abroad counterparts. Though Asia accounts for only 6 percent of the total number of students studying abroad according to the 2001/01 Open Doors report, nearly 37 percent of 
Frontiers: The Interdisciplinary Journal of Study Abroad

all Asian Americans in this study went to an Asian country. Travel was concentrated in Asia for both groups, supporting the belief that travel often includes trips to regions of common ancestry and language heritage.

However, the recommendation of a friend, which is significant for the general study abroad population, does not play as significant a role for Asian Americans. Anecdotal evidence maintains that returned students are one of the best sources of promotion for study abroad programs.

Analysis regarding the experiences of Asian Americans abroad revealed that the majority of students experienced at least one major challenge while abroad, including homesickness, blatant racial discrimination, communication issues and difficulty adjusting to the lack of a structured environment. Support services across the board received an "average" rating, indicating that Asian American students do not believe extra efforts are being made to meet their needs.

Several factors that influence Asian Americans are important to compare to African American students who consider study abroad. Three factors that inhibit African Americans from studying overseas are financial concerns, university attrition rates and the fear of discrimination. ${ }^{18}$ For Asian Americans, the financial concerns were only important to those who did not go abroad. Among the U.S. population, Asian Americans have the highest retention rates of all ethnic groups in both two-year and four-year academic institutions. ${ }^{19}$ Thus, the attrition rate is not a significant factor influencing an Asian American's decision to study abroad. In terms of discrimination, the Asian American Study Abroad group reported racism and challenges while studying abroad, but for the Non-Study Abroad group, fear of a new culture and fear of discrimination abroad ranked at the bottom of factors influencing their decision to study abroad. Asian Americans do not list peer recommendation as one of the factors influencing their decision. The challenges and racial discrimination experienced by those Asian Americans who went overseas might not be relayed back to the general Asian American population. It also is possible that the other factors keep some Asian American students from going abroad are more salient than the challenges and racial discrimination they might face. Thus, the factors influencing African Americans are not the same as those for Asian Americans.

This study reveals that the factors that prevent Asian Americans students from going abroad are not the same factors that motivate students 


\section{J. Scott Van Der Meid}

who do go abroad. This suggests that Asian American students who go overseas do not participate in study abroad because they have found a solution to financial and academic challenges faced by those who do not go. Rather, the students seek the study abroad experience for other reasons, such as to learn a foreign language and culture. Academic compatibility was the number one issue for Non-Study Abroad students, yet the factor ranked sixth on the list of reasons that Asian American students went overseas. However, two factors are in direct contrast to each other: the fear of cultural differences by those who did not study abroad and the desire to learn about a new culture by those who did go overseas. This provides further support for the conclusion that Study Abroad students are more adventurous and motivated, while Non-Study Abroad students are more cautious.

Factors which influence Asian American students to study abroad include major field of study, sex, ethnicity, financial resources, location of study abroad programs, and the experiences of previous Asian American study abroad students, with specific reference to challenges and racial discrimination. Academics influence those who do not go abroad but are of secondary importance for those who go abroad.

\section{Implications of Results}

With such a small percentage of students partaking in some form of study abroad in the United States, there is a continuing interest in finding ways to increase the amount of students sent overseas. ${ }^{20}$ By looking at the various ethnic minorities, universities and colleges can increase the student applicant pool for their study abroad programs. Reaching untapped markets and learning more about the demographics of the potential participants is a common business practice that needs more careful consideration in the field of study abroad. Related to understanding the potential participant pool, more emphasis should be placed on promoting to the Asian American community the idea that study abroad should be an integral component of a higher education experience. If study abroad offices and Asian American student groups do not encourage study abroad by promoting the opportunities to do so, Asian Americans will continue not to view study abroad as an option for them.

Since the top three major fields of study for Asian Americans are the same top three fields among Asian Americans who do not study abroad, 
Frontiers: The Interdisciplinary Journal of Study Abroad

efforts should be made to find ways to promote study abroad for students in those majors. Finding academic programs that will allow students to take courses overseas without sacrificing their academic timetable is important. This is no different than it is for the general study abroad population. Thus it would seem that, in addition to better promotion, integration of more major fields into study abroad, programs will increase the number of Asian Americans who go overseas.

Because the plurality of Asian Americans opt to study abroad in Asian countries, more emphasis should be placed on creating study abroad opportunities in this region. The students' desire to learn about a new culture, improve their language skills and to learn about their cultural heritage would support these options. In addition, it is important to offer programs of differing lengths so that students have options in terms of how long they wish to be away from the United States.

\section{Limitations of the Study and Future Research Areas}

Several aspects of this study placed limitations on the type and scope of information available for analysis. First and primary was the student sample size. While the aim was to have a sample of 80 students for both groups, this proved to be statistically insufficient. The Asian American category combines many different sub-ethnic groups of Asian background. This study, however, contained almost none of the ethnic groups from the lower end of the socio-economic spectrum, nor those who have recently immigrated to the United States. Instead, this study can speak only to the more established Asian ethnic groups in the U.S., the Chinese, Japanese and Koreans.

Two other demographic issues limit the study as well. Over 39 percent of Asian Americans are enrolled in two-year community colleges: this study speaks primarily for Asian Americans enrolled in private, four-year academic institutions. A study that targets Asian American students attending community colleges would provide valuable information about that population. Further, nearly 82 percent of Asian American students nationwide are enrolled in public institutions. Since the majority in this study came from private universities and colleges, the study does not speak for Asian Americans on a national level. 


\section{J. Scott Van Der Meid}

No research on the time frame of initial interest in study abroad exists for the general study abroad population, but some colleagues have suggested that under-represented populations might need earlier encouragement about how study abroad is a viable option for them. This study's findings indicate that more than 63 percent of all Asian American students who studied abroad had become interested by the time they finished high school, and the plurality of students (42\%) learned about such opportunities during high school. The Non-Study Abroad group had a 100-percent response rate regarding awareness of study abroad, which is due, in part, to the fact that students volunteered to take this questionnaire and, thus, already had some interest in the topic. This makes it difficult to assess the actual awareness of study abroad among the general Asian American student community.

Greater access to the questionnaires was achieved by placing the questionnaires on the Web, but this also proved to be a limitation. Since most of the students contacted who had studied abroad were excited to learn about this study, they readily provided answers. The Non-Study Abroad student group, by the nature of the study, was composed of those interested in the topic and willing to fill out the questionnaire. Those Asian American students, who did not care about the topic, simply did not have to participate, and, therefore, their views are not represented in the findings. Future studies should contact classrooms or other environments with Asian American students in order to have a more representative sample.

Further research will need to look at the other dependent variables regarding the experience of racism overseas. How do different ethnic groups and/or sexes overseas experience racism differently? Does the country of destination have any impact on the amount or kind of racism students experience? What can be done to help Asian Americans deal with the racism that they encounter? Given that the majority of Asian American students going overseas are female, why do so few men participate in study abroad? Examining the lives and experiences of Asian American students on their overseas programs is another area for future research. How do Asian American students adjust overseas compared to the general study abroad population? Do they have more difficulties? Should programs consider a different configuration of on-site support services for Asian Americans? What issues seem to be most salient for Asian Americans while overseas? 
Frontiers: The Interdisciplinary Journal of Study Abroad

Finally, conducting research on the long-term effects of the study abroad experience on Asian Americans, as well as the general study abroad population, is critical. What effect does study abroad have on future careers, and other areas of students' lives? Until we know the long-term outcomes of study abroad programs, we will not have a full understanding of the implications for students' decisions to study abroad.

\section{Notes}

${ }^{1}$ Lott, Juanita. Asian Americans: From Racial Category to Multiple Identities. (Walnut Creek, CA: Altamirea Press, 1998), p. 27-8.

${ }^{2}$ Ronald Takai's book Strangers from a Different Shore provides a reliable historical overview of Asian Americans in the United States, from the time of immigration to present day situations.

${ }^{3}$ Eugenia Escueta and Eileen O'Brien, Asian Americans in Higher Education. (Washington, D.C.: American Council on Education, 1991), 2-3.

${ }^{4}$ Ibid., 1.

5 Ibid., 1.

6 Holly Carter, Minority Access to International Education. (Washington, D.C.: CIEE, 1991), 15-17.

${ }^{7}$ P. Rudy Mattai and Godwin Ohiwerei. Some Mitigating Factors Against African Americans in the Rural American South Opting to Study Abroad. (Washington, DC: CIEE, 1989), 6.

${ }^{8}$ See Min, p. 45, for issues regarding the importance of family and the changes taking place within Asian families in the U.S. cultural setting.

${ }^{9}$ Jayjia Hsia, Asian Americans In Higher Education and at Work, (Hillside, NJ: Lawrence Erlbaum Associates, Publishers, 1988), 129, 205.

${ }^{10}$ Asian Americans made up more than 68 percent of the total enrollment of students in Hawaii in 1984. Hsia, 126.

${ }^{11}$ Rudy Mattai and Godwin Ohiwerei, 4.

${ }^{12}$ Eugenia Escueta and Eileen O'Brien. Asian Americans in Higher Education. (Washington, D.C.: American Council on Education, 1991), 3.

${ }^{13}$ U.S. Department of Education, National Center for Education Statistics, http://nces.ed.gov/fastfacts/436.asp?type=3\#higher, 1995 .

${ }^{14}$ Escueta and O'Brien, 3.

15 Todd Davis. Open Doors 1996/97. (New York: IIE, 1998), 154.

${ }^{16}$ Escueta and O'Brien, 8. 
${ }^{17}$ Mattai and Ohiwerei, 6-7.

18P. Rudy Mattai and Godwin Ohiwerei. 6.

${ }^{19}$ Jayjia Hsia, 132.

20 Although not outlining reasons for students to go overseas, "Promoting Student Diversity" in NAFSA's Guide to Education Abroad discusses strategies study abroad professionals can implement to increase minority participation such as building faculty support, working closely with student services, furnishing role models, beginning early, working with parents and using returned students.

\section{Sources}

Burn, Barbara B., ed. Integrating Study Abroad into the Undergraduate Liberal Arts Curriculum. New York: Greenwood Press, 1991.

Carter, Holly. "Minority Access to International Education" in Black Students and Overseas Programs: Broadening the Base of Participation. Council on International Educational Exchange, 9-20. New York: CIEE, 1991. Dialog, ERIC, ED 340323.

Council on International Education Exchange. Increasing Participation of Ethnic Minorities in Study Abroad. New York: Council on International Education Exchange, 1991. Dialog, ERIC, ED 346 784.

Craig, Starlett. "Study Abroad Matters: Top 10 Reasons for African American Students to Go Abroad". Transitions Abroad. Vol. 22, No. 1, pp. 89-91, 1998.

Davis, Todd. Open Doors 1996/97: Report on International Education Exchange. New York: Institute of International Education (IIE), 1998.

Dudley, William, ed. Asian Americans: Opposing Viewpoints. San Diego: Greenhaven Press, Inc., 1997.

Escueta, Eugenia and Eileen O'Brien. Asian Americans in Higher Education: Trends and Issues. Washington, D.C.: American Council on Education, 1991.

Ganz, Margery A., Jack Osborn, and Paula Primak. "Promoting Student Diversity." In NAFSA's Guide to Education Abroad For Advisors and Administrators, ed. William Hoffa, John Pearson, and Marvin Slind, 111-123. Washington, DC: NAFSA, 1993. 
Frontiers: The Interdisciplinary Journal of Study Abroad

Greenfield, Patricia M. and Rodney R Cocking. Cross-Cultural Roots of Minority Child Development. Hillsdale, NJ: Lawrence Erlbaum Associates, Publishers, 1994.

Hembroff, Larry A. and Debra L. Rusz. "Minorities and Overseas Studies Programs: Correlates of Differential Participation". New York: Council on International Education Exchange, 1993. Dialog, ERIC, ED 368283.

Hoffa, William, John Pearson, and Marvin Slind, eds. NAFSA's Guide to Education Abroad for Advisors and Administrators. Washington, DC: NAFSA: Association for International Educators, 1993.

Hsia, Jayjia. Asian Americans in Higher Education and at Work. Hillsdale, NJ: Lawrence Erlbaum Associates, Publishers, 1988.

Lott, Juanita T. Asian Americans: From Racial Category to Multiple Identities. Walnut Creek, CA: Altamirea Press, 1998.

Martin, Judith and Beulah Rohrlich. "The Relationship between Study Abroad Student Expectations and Selected Student Characteristics". Journal of College Student Development, Vol. 32, No. 1, pp. 39-46, Jan. 1991.

Mattai, P. Rudy and Godwin Ohiwerei. Some Mitigating Factors against African-Americans in the Rural American South Opting to Study Abroad. New York: Council on International Educational Exchange, 1989. ERIC, ED 315474.

Min, Pyong Gap, ed. Asian Americans, Contemporary Trends and Issues. Thousand Oaks, CA: Sage Publications, 1995.

Open Doors 2000/01: Report on International Education Exchange. New York: Institute of International Education (IIE), 2003. www.opendoors.iienetwork.org/?p=25191

Siu, Sau-Fong W. Asian American Students At Risk: A Literature Review. Center For Research on the Education of Students Placed At Risk, 1996.

Takaki, Ronald. Strangers From A Different Shore: A History of Asian Americans. New York: Penguin Books, 1989.

Takayi, Dana Y. The Retreat from Race: Asian-American Admissions and Racial Politics. New Brunswick, NJ: Rutgers University Press, 1992.

U.S. Department of Commerce, Bureau of the Census. Asian and Pacific Islander Population by States: 1980. Washington, D.C.: U.S. Government Printing Office, 1983. 


\section{J. Scott Van Der Meid}

U.S. Department of Education, National Center for Education Statistics, Digest of Education Statistics, 1997.

Walker-Moffat, Wendy. The Other Side of the Asian American Success Story. San Francisco: Jossey-Bass Publishers, 1995.

Wang, L. Ling-chi. "Trends in Admissions for Asian Americans in Colleges and Universities: Higher Education Policy." In The State of Asian Pacific America: A Public Policy Report, Los Angeles: LEAP Asian Pacific American Public Policy Institute and UCLA Asian American Studies Center, 1993. 